\title{
Synthesis and Photoresponsive Properties of a Molecularly Imprinted Polymer
}

\author{
Christophe Gomy and Andreea R. Schmitzer
}

Department of Chemistry, Université de Montréal, C.P. 6128

Succursale Centre-ville, Montréal, Québec, H3C 3J7 Canada.Phone : (+1) 514-343-6744;

Fax: (+1) 514-343-7586 


\section{Experimental procedures}

Materials and Apparatus. Chemicals were purchased from Aldrich and used as received unless otherwise indicated. All nonaqueous reactions were run under an inert atmosphere (nitrogen or argon) with strict exclusion of moisture from reagents. Anhydrous solvents were obtained by filtration through drying columns (THF, toluene) on a GlassContour system (Irvine, CA). Analytical thin-layer chromatography (TLC) was performed on precoated, glass-backed silica gel (Merck 60 F254). Visualization of the developed chromatograms was performed by UV absorbance, aqueous cerium molybdate, ethanolic phosphomolybdic acid, iodine, or aqueous potassium permanganate. Flash column chromatography was performed using 230-400 mesh silica (EM Science or Silicycle) using the indicated solvent system according to standard technique. Melting points were obtained on a Buchi melting point apparatus and are uncorrected. Nuclear magnetic

resonance spectra $\left({ }^{1} \mathrm{H},{ }^{13} \mathrm{C}\right)$ were recorded on a Bruker AV 300 spectrometer. Chemical shifts for ${ }^{1} \mathrm{H}$ NMR spectra were recorded in parts per million from tetramethylsilane with the solvent resonance as the internal standard. Data are reported as follows: chemical shift, multiplicity $(\mathrm{s}=$ singlet, $\mathrm{d}=$ doublet, $\mathrm{t}=$ triplet, $\mathrm{q}=$ quadruplet and $\mathrm{m}=$ multiplet $)$, coupling constant in $\mathrm{Hz}$, integration and assignment. Chemical shifts for ${ }^{13} \mathrm{C} \mathrm{NMR}$ spectra are recorded in parts per million from tetramethylsilane using the central peak of deuterochloroform $(77.23 \mathrm{ppm})$ as the internal standard. Analytical gas chromatography was carried out on a Hewlett Packard 5880A gas chromatograph equipped with a splitless mode capillary injector and a flame ionization dectector or with an Agilent 6890 Series GC system equipped with an Agilent 5973 EI mass detector. Absorption measurements were done on a Varian Cary-100 spectrometer.

\section{Synthesis of trans-di(ureidoethylenemethacrylate)azobenzene (1)}

p-Phenylenediamine $(1 \mathrm{~g}, 9 \mathrm{mmol})$ in $75 \mathrm{ml}$ dry $\mathrm{THF}$ was stirred with $\mathrm{KO}_{2}$ potassium superoxide $(2,7 \mathrm{~g} 36 \mathrm{mmol})$ at $65{ }^{\circ} \mathrm{C}$ for 6 hours. After filtration and solvent evaporation, the dark yellow azobenzene-4,4' diamine was purified on silica column, using $100 \%$ ethylacetate as eluent. (45\% yield) ${ }^{1} \mathrm{H}$ NMR $\left(\mathrm{D}_{2} \mathrm{O}\right): 5.75(\mathrm{~s}, 4 \mathrm{H}), 6.62(\mathrm{~d}, J=8.4 \mathrm{~Hz}, 4 \mathrm{H}), 7.52$ (d, J=8.8 
$\mathrm{Hz}, 4 \mathrm{H})$. To a dry THF solution ( $30 \mathrm{~mL}$ ) of azobenzene-4,4'-diamine $(20 \mathrm{mmol})$ was added a solution of 2-isocyanatoethyl methacrylate $(50 \mathrm{mmol})$ in dry THF $(50 \mathrm{~mL})$ under nitrogen atmosphere. The solution was stirred at room temperature for $24 \mathrm{~h}$ and the solvent was then evaporated under reduced pressure. The resulting yellow solid was washed with petrol and recristallized from acetone as yellow pellets. Yield:54\%. ${ }^{1} \mathrm{H}$ NMR (trans-1, DMSO- $\mathrm{d}_{6}$ ) d: $1.86(\mathrm{~s}, 6 \mathrm{H}), 3.39$ (t, $J=6.0 \mathrm{~Hz}, J=5.0 \mathrm{~Hz}, 4 \mathrm{H}), 4.11(\mathrm{t}, J=5.2 \mathrm{~Hz}, 4 \mathrm{H}), 5.68(\mathrm{~s}, 2 \mathrm{H}), 6.06$ (s, 2H), 6.41 (t, J = 5.8 Hz, 2H), $7.56(\mathrm{~d}, \mathrm{~J}=7.6 \mathrm{~Hz}, 4 \mathrm{H}), 7.73(\mathrm{~d}, \mathrm{~J}=10.4 \mathrm{~Hz}, 4 \mathrm{H}), 8.96(\mathrm{~s}$, $2 \mathrm{H}) ;{ }^{13} \mathrm{C}$ RMN (100 MHz, DMSO- $\left.d_{6}\right) \delta: 17.4,42.8,63.1,128.5,128.6,128.9,135.4,142.9$, 150.6, 156.42, 166.1; +TOF MS, $[\mathrm{M}+\mathrm{H}]^{+}$, calc. 523.22, found 523.23.

\section{${ }^{1}$ H NMR Spectroscopic Titration Studies}

Proton NMR spectroscopy-based titration studies were carried out using a Bruker Avance AMX 400 spectrometer at $400 \mathrm{MHz}$. The monomer solutions were titrated by adding known quantities of a concentrated solution of the bis(TBA) N-Z-L-glutamate anions. Increasing the concentration of anion in the host-guest mixture solution induced a clear downfield shift in the ureas NH peak (as shown in Figure S1). Fitting the observed data points to a 1:1 binding profile (see Figure S1), using Microcal Origin 6.0, gave the extrapolated complex-induced chemical shifts.

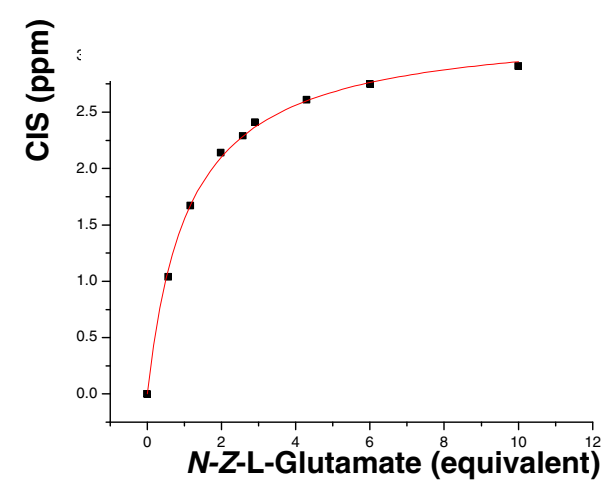

Cis-1 Outer ${ }^{1} \mathrm{H}$

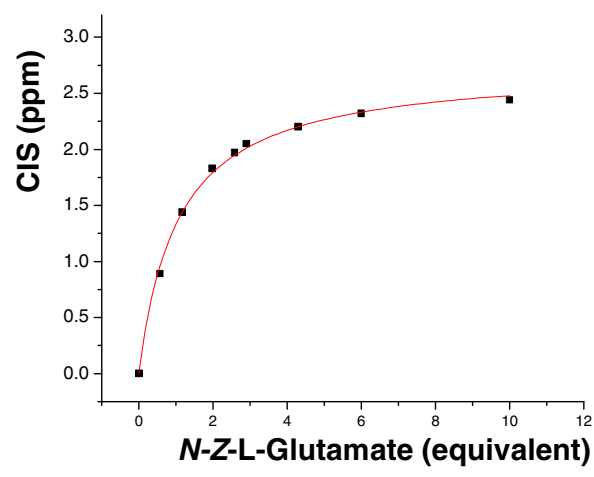

Cis-1 Inner ${ }^{1} \mathrm{H}$

Figure S1 : ${ }^{1} \mathrm{H}$ NMR spectra obtained from the complexation study for 1 with $N$-Z-Lglutamate. Fitting of the observed chemical shifts of 1 to a 1:1 binding profile, using Microcal Origin 6.0. 
The cis isomer was obtained by irradiation at $365 \mathrm{~nm}$ of the NMR tube. We followed the complexation induced shifts of the outer urea protons for both isomers present in solution (60/40 trans/cis). Increasing the concentration of anion in the host-guest mixture solution induced a clear downfield shift in the ureas NH peak. Fitting the observed data points to a 1:1 binding profile, using Microcal Origin 6.0, gave the extrapolated complex-induced chemical shifts.

\section{Titration under UV irradiation}

The monomer solutions were titrated by adding known quantities of a concentrated solution of the bis(TBA) $N$-Z-L-glutamate anions, under irradiation at $365 \mathrm{~nm}$. Increasing the concentration of anion in the host-guest mixture solution induced an inversion of the isomers ratio, as shown is Figure $\mathrm{S} 2$. The observation of a shift in the cis/trans ratio by the bis(TBA) $N$-Z-L-glutamate, gives good evidence for a selective interaction of the bis(TBA)N$Z$-L-glutamate with cis-isomer over the trans-isomer.

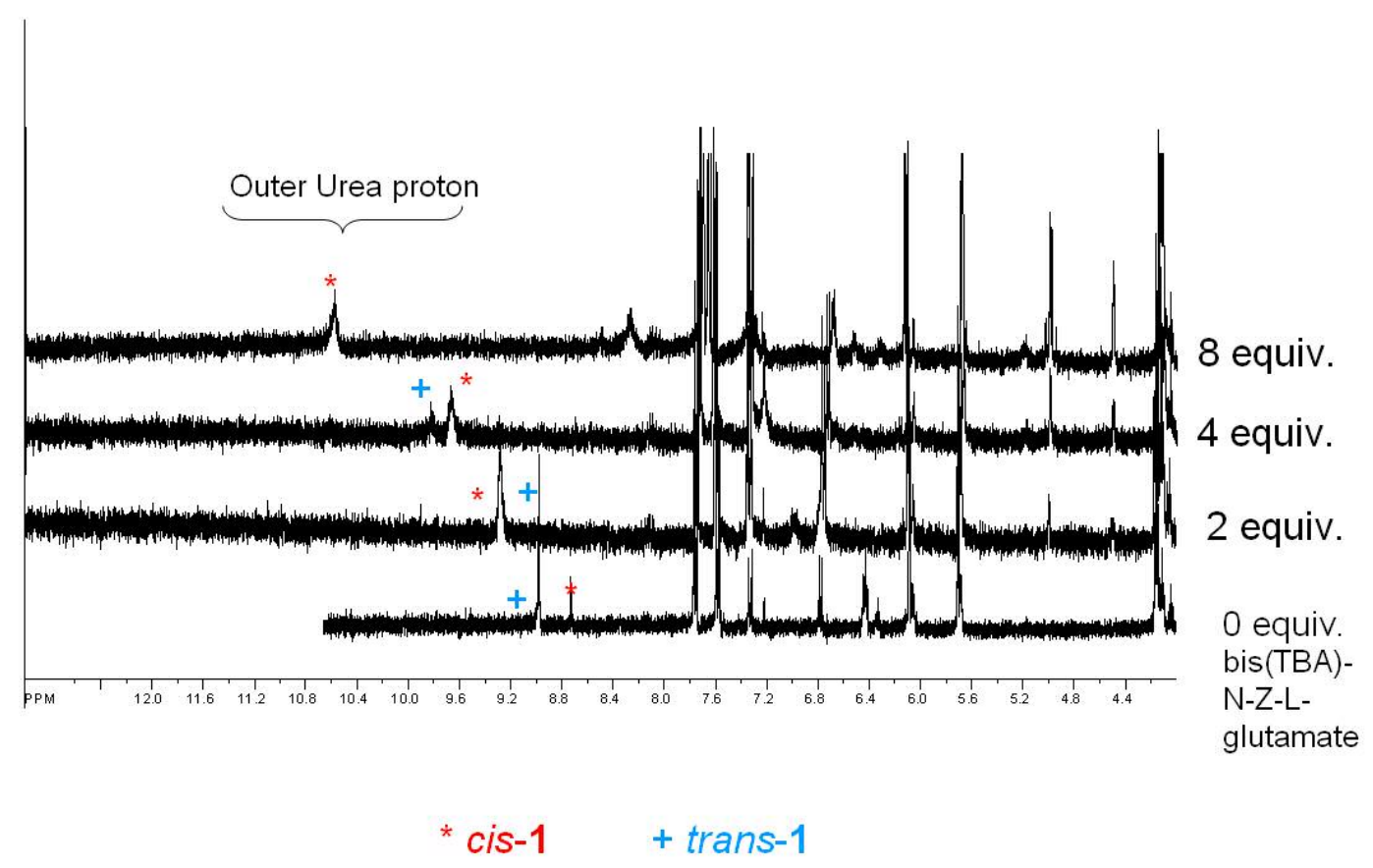

Figure S2: Partial 1H NMR spectra (400 MHz, 298K) of monomer 1 after 20 minutes irradiation at $365 \mathrm{~nm}$.

Polymerization : General procedure. The radical polymerization of the bismethacrylated monomer $1(0.2-2.0 \mathrm{mmol})$ was performed in DMSO solvent $(10 \mathrm{~mL})$ with ethyleneglycol dimethacrylate (EDMA) $(20 \mathrm{mmol})$ at $40^{\circ} \mathrm{C}$ and 2,4-dimethylvaleronitrile (ABDV) as initiator $(1 \% \mathrm{w} / \mathrm{w}$ total monomers) was added. The solution was transferred into a $20 \mathrm{ml}$ conical flask tube, capped and purged with nitrogen for 15 min. The radical polymerization 
was initiated thermically by placing the tube in an oil bath thermostated at $40{ }^{\circ} \mathrm{C}$. Vigorous magnetic agitation was allowed to process for $25 \mathrm{hrs}$. The resultant bulk polymer was of elastic breakable aspect and was crushed, milled and wet-sieved in methanol through a $48 \mu \mathrm{m}$ sieve and collected by centrifugation. Imprint molecules were removed by Soxhlet extraction with Methanol/Acetonitrile/Acetone for 48 hours, followed by drying under high vacuum at $70^{\circ} \mathrm{C}$. The control polymer material (non-imprinted) was prepared and treated in exactly the same way as the MIP, except that the imprint molecule was omitted during the polymerization procedure.

\section{Spectroscopic characterization and photoisomerization studies}

Spectroscopic characterization of the functionalized azobenzene monomer and the subsequent MIP materials was performed in DMSO. For the polymers, all photoisomerization studies were performed with $1 \mathrm{mg}$ of polymer in $3 \mathrm{ml}$ of DMSO, into a screw-capped quartz cell, at $25^{\circ} \mathrm{C}$ in a Cary100 spectrophotometer (Varian).

\section{MIP Rebinding Assay}

Binding properties of the MIP and control materials were studied using batch-type rebinding assays in DMSO. The amount of substrate left after rebinding was determined by GC-MS. All rebinding assays were performed with MIP material $(10 \mathrm{mg})$ in DMSO $(2 \mathrm{ml})$ at room temperature. In a typical rebinding experiment, $10 \mu$ moles of substrate was spiked into suspensions of MIP material in $20 \mathrm{ml}$ crew-cap vials. These suspensions were then sealed and agitated for 48 hours. The suspension was then centrifugated at $10000 \mathrm{rpm}$ for $20 \mathrm{~min}$ and $1.0 \mu \mathrm{l}$ of the supernatant was analyzed by GC-MS using a $30 \mathrm{~m} \mathrm{HP}-5,5 \%$ phenylmethylsiloxane capillary column. The substrate was identified by its mass spectrum. External calibration using standard solutions of substrate ranging from 0 to $10 \mu \mathrm{M}$ was adopted to quantify its concentration in the solution.

\section{Density and binding strength of MIP}

According to Langmuir isotherm model, the association constant and binding site density were estimated graphically from a linearised version of the binding isotherm. This was done by plotting the binding isotherm in a Scatchard format as bound/free template ratio 
$\left(\mu \mathrm{mol} / \mathrm{mg}_{\text {polymer }}\right)$ versus bound template $\left(\mu \mathrm{mol} / \mathrm{g}_{\text {polymer }}\right)$. Each linear region of the binding isotherm was fitted with a straight line. The association constant and binding site density were calculated from the slope and the $y$-intercepts, respectively, according to the equation: $\frac{B}{F}=K_{i} Q_{\mathrm{s}}-K_{a} B$, where $B$ is amount of the template bound to polymer, $F$ is concentration of free template, $Q_{\mathrm{S}}$ is site density and $K_{\mathrm{a}}$ is association constant.

\section{Photoregulated Uptake and Release Studies}

In all photoregulated release and uptake studies, empty MIP or control material (10 mg) was added to a DMSO solution $(2 \mathrm{ml})$ containing $10 \mu$ moles of substrate. In a typical uptake run, the MIP suspension was kept under agitation and UV irradiation at $365 \mathrm{~nm}$ in a Luzchem (LZC-5) reactor with 6 lamps ( $8 \mathrm{~W}$ each) for 2 hours. After this period, the suspension was centrifugated in the dark at $10000 \mathrm{rpm}$ for $20 \mathrm{~min}$ and $1.0 \mu \mathrm{l}$ of the supernatant was analyzed by GCMS using a $30 \mathrm{~m}$ HP-5, 5\% phenylmethylsiloxane capillary column. The same polymer/substrate solution was kept under agitation and irradiated at $440 \mathrm{~nm}$ for 2 hours and the amount of the free substrate analyzed again. 


\section{Product Characterization}

${ }^{13} \mathrm{C} 100 \mathrm{MHz}$ in DMSO-d ${ }^{6}$

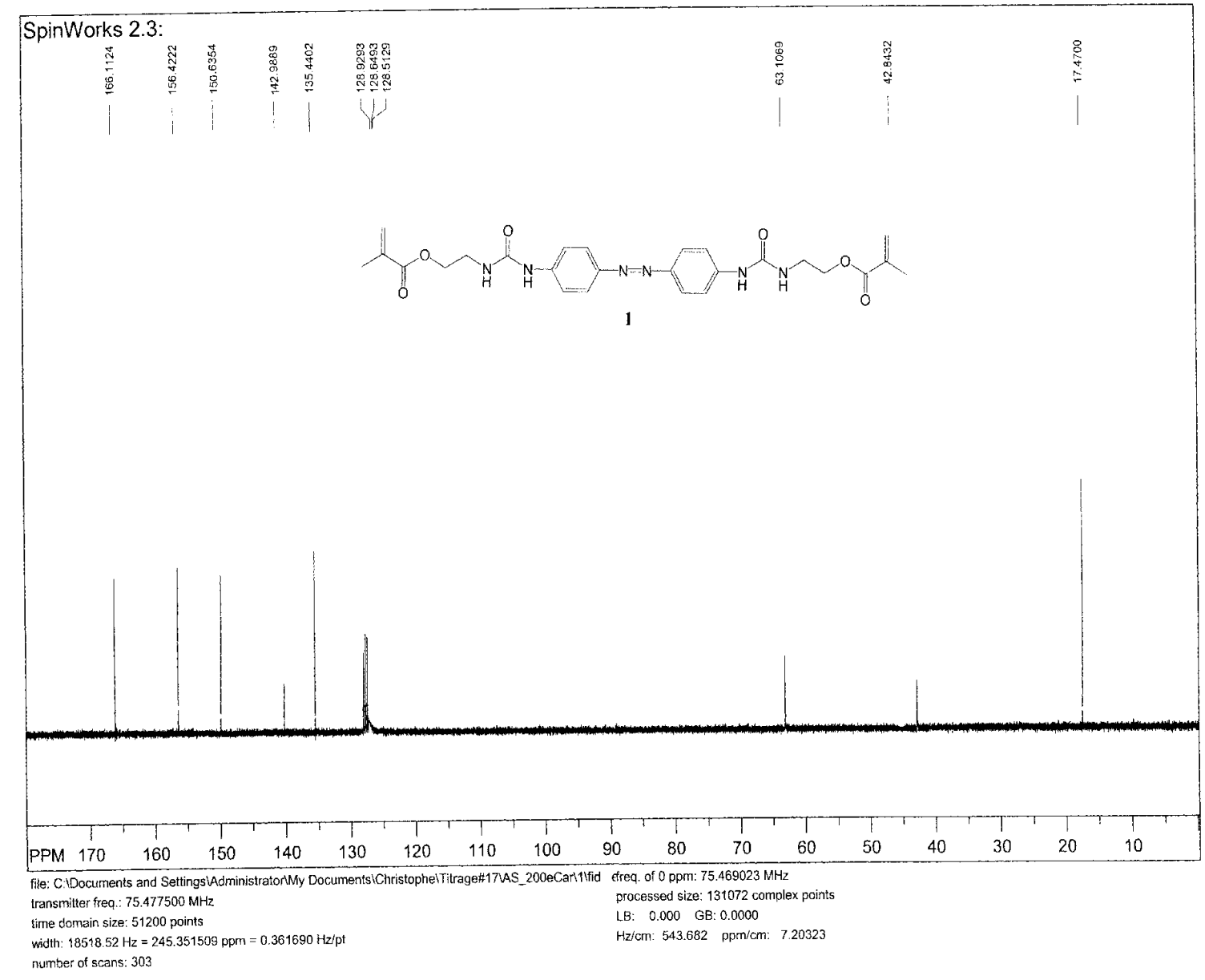




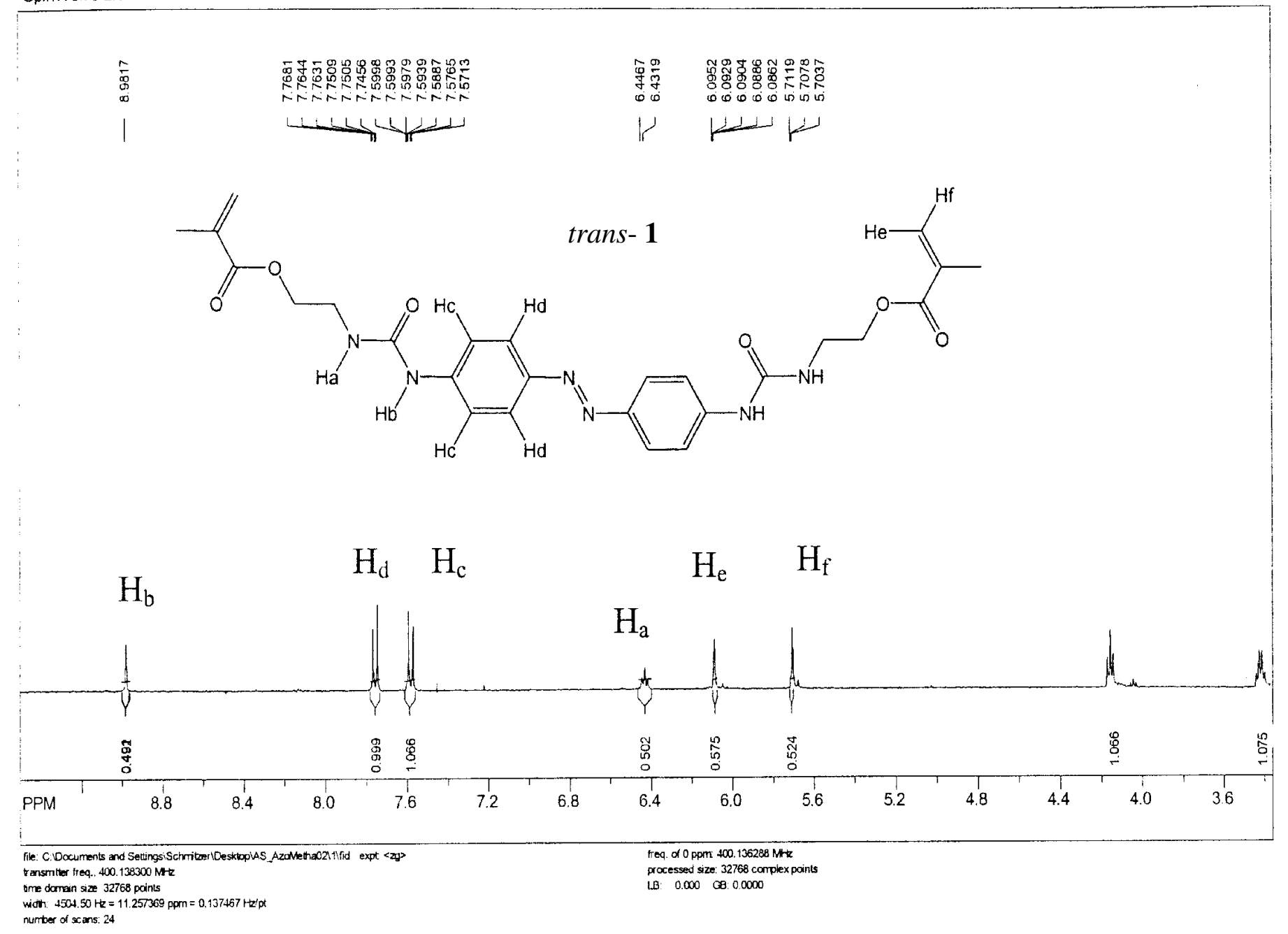



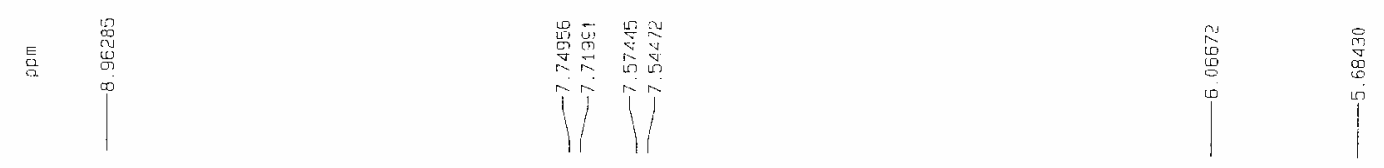

trans- $\mathbf{1}$

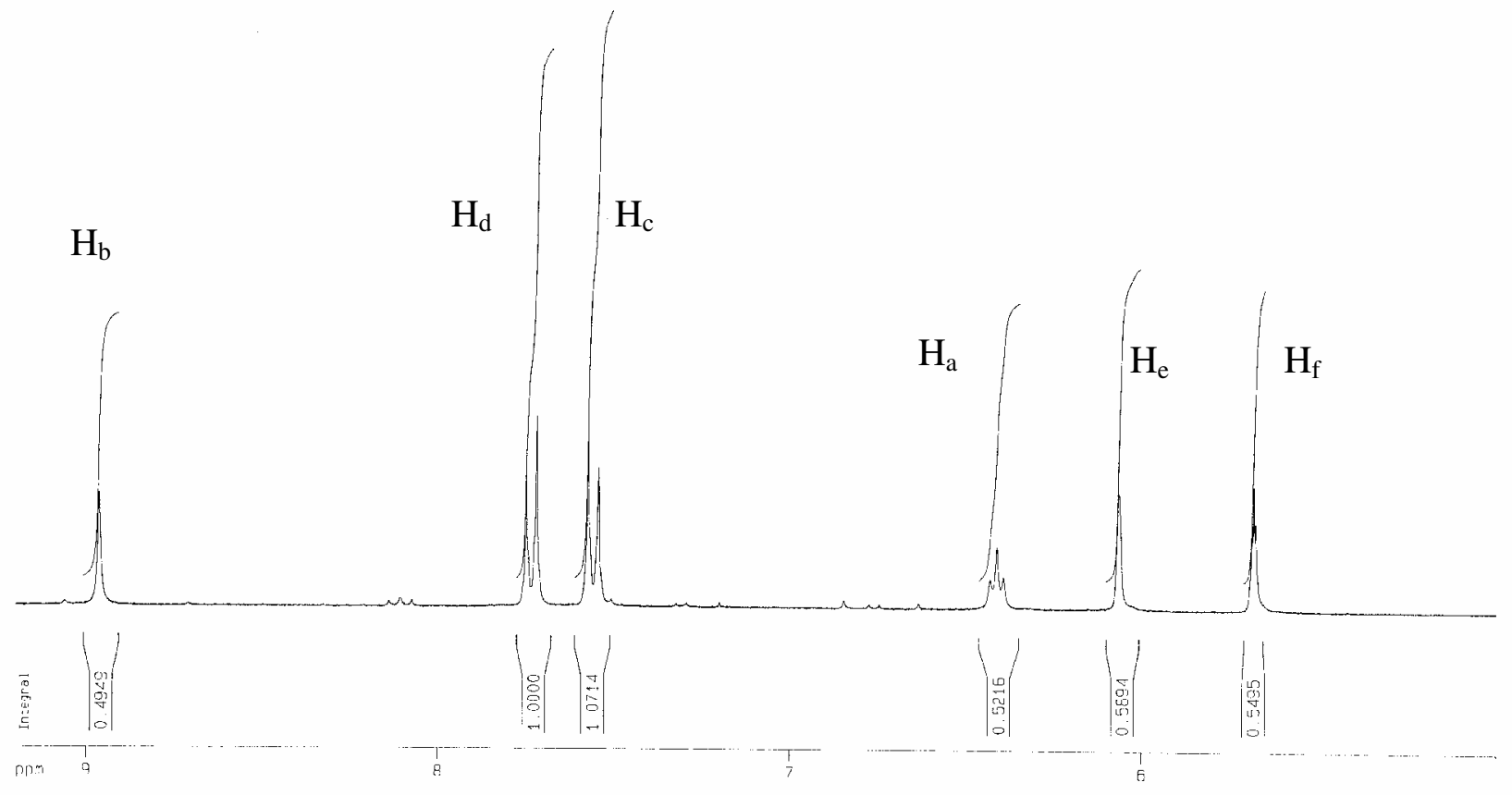



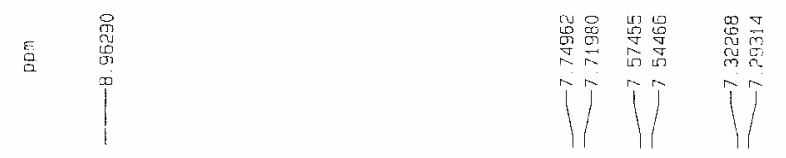

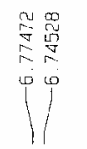

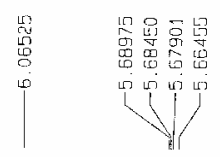

Mixture of $40 \%$ cis- 1 and $60 \%$ trans-1

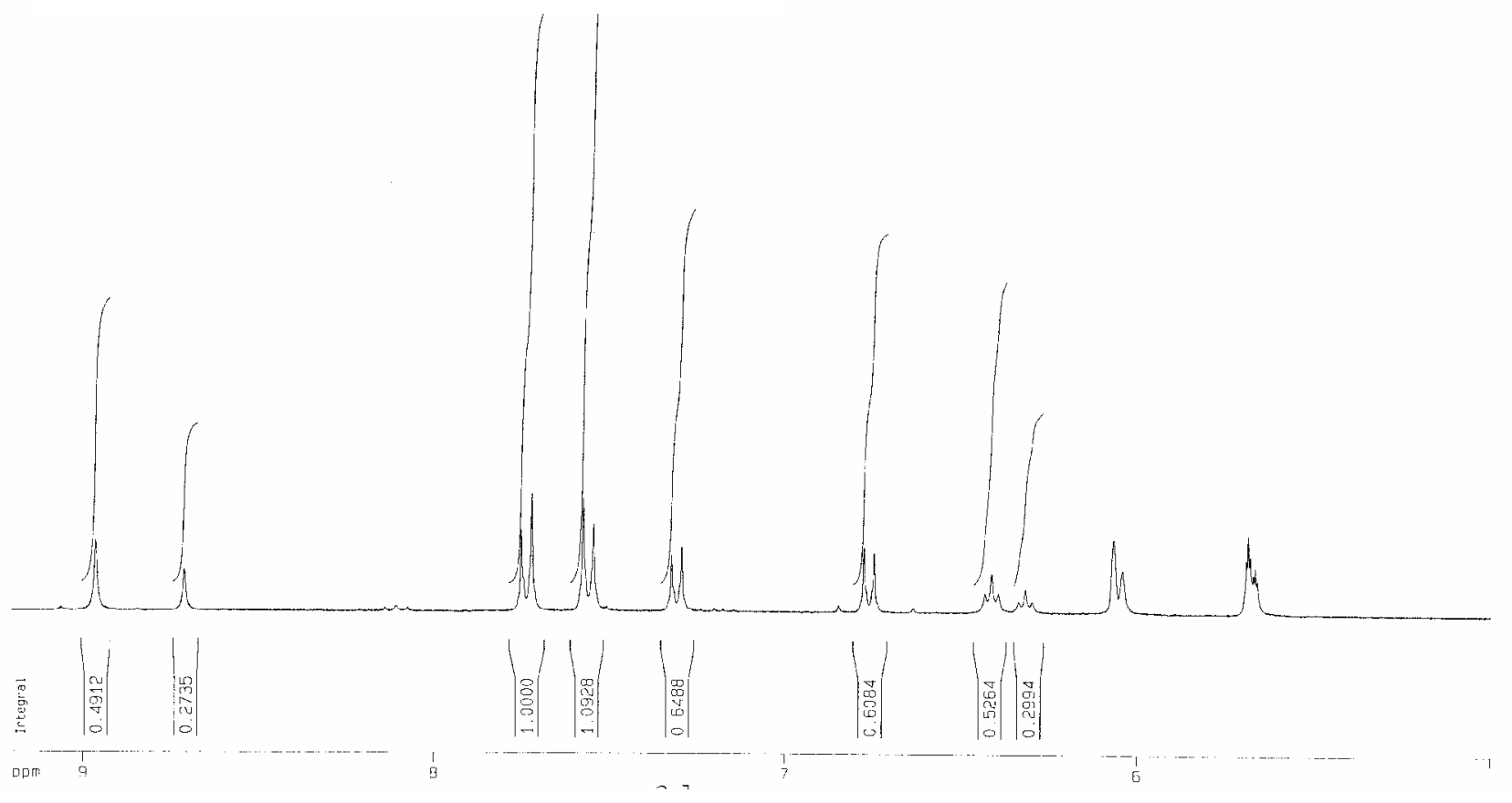



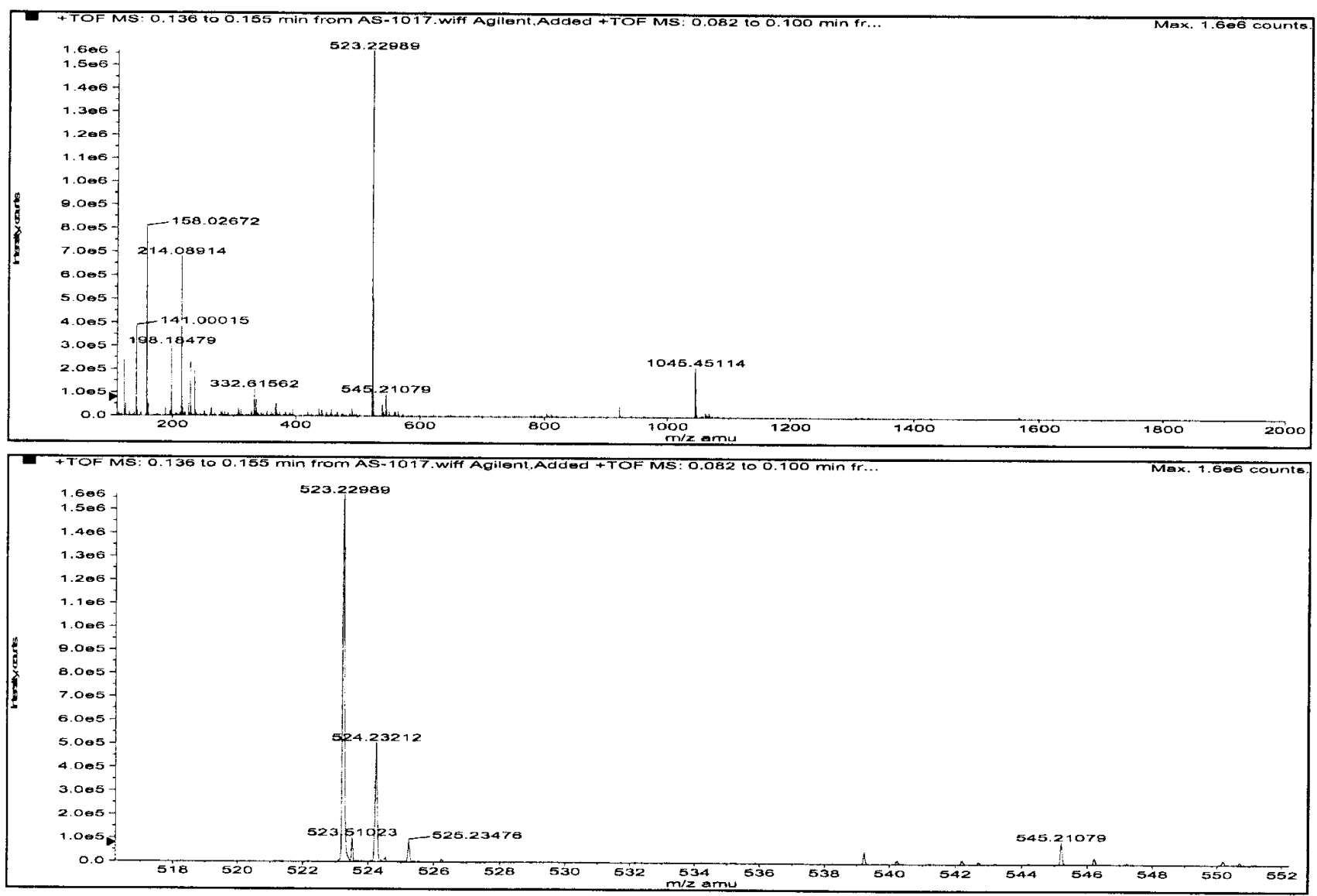

\begin{tabular}{|c|l|c|r|r|r|}
\hline Formula & Compound name & Mass & Peak RT (min) & Peak area & Description \\
\hline $\mathrm{C} 26 \mathrm{H} 30 \mathrm{~N} 606$ & - & 522.22268 & 0.11 & $1.60369 \mathrm{E} 7$ & - \\
\hline
\end{tabular}

\begin{tabular}{|l|r|r|r|r|r|r|}
\hline Species & Abundance (counts) & lon Mass & Measured Mass & Error (mDa) & Error (ppm) & Ret. Time Error (min) \\
\hline$[\mathrm{M}+\mathrm{H}]^{+}$ & 1648563.45 & $\mathbf{5 2 3 . 2 2 9 9 6}$ & 523.22989 & -0.00007 & -0.13 & - \\
\hline$[\mathrm{M}+\mathrm{Na}]^{+}$ & $\mathbf{9 5 3 2 1 . 4 2}$ & $\mathbf{5 4 5 . 2 1 1 9 0}$ & 545.21079 & -0.00111 & -2.04 & - \\
\hline
\end{tabular}

